\title{
PHOSPHORUS IN SINTERED STEELS: INTERACTION OF PHOSPHORUS WITH Mo
}

\author{
H. Danninger, B. Üregen
}

\begin{abstract}
Phosphorus as an alloy element is quite common in powder metallurgy, the contents industrially used being markedly higher than those present in wrought steels. However, embrittlement effects are reported also for sintered steels, in part depending on the alloy elements present. In this study, the influence of phosphorus addition on the mechanical properties of PM steels alloyed with Mo, as the most common VI group element in sintered steels, was investigated. PM steels of the type Fe-x\%Mo-0.7\%C$y \% P$ were manufactured with varying contents of Mo and $P$, respectively. It showed that $P$ activates sintering also in these materials and enhances Mo homogenization, but there is in fact a risk of embrittlement in these steels that however strongly depends on the combination of Mo and P in the materials: If a critical level is exceeded, embrittlement is observed. At low Mo contents, higher $P$ concentrations are acceptable and vice versa, but e.g. in a material $\mathrm{Fe}-1.5 \% \mathrm{Mo}-0.7 \% \mathrm{C}-0.45 \% \mathrm{P}$, pronounced intergranular embrittlement occurs, further enhanced by sinter hardening effects. This undesirable phenomenon is more pronounced at higher sintering temperatures and in case of faster heating/cooling; it was observed both in materials prepared from mixed and prealloyed powders, respectively. This typical intergranular failure observed with embrittled specimens, in particular after impact testing, indicates the precipitation of brittle phases at the grain boundaries, apparently when exceeding the solubility product between Mo and $P$.
\end{abstract}

Keywords: Sintered steel, phosphorus, molybdenum, embrittlement

\section{Introduction}

While phosphorus is a highly undesirable component in wrought steels the content of which is kept at as low levels as possible, it is frequently added to PM steels in considerable levels, typically up to 0.6 mass\%. In ingot metallurgy, the pronounced tendency of $P$ to segregation, supported by the very low-melting eutectic Fe-P, causes severe problems, and typical P levels in wrought steels are $<$ e.g. $0.01 \%$, except some transformer core steel sheet grades which may contain up to $0.1 \%$, which is however still much less than the phosphorus contents common in powder metallurgy. For PM steels the beneficial activating - effect of $\mathrm{P}$ on the sintering of ferrous materials is used which e.g. in PM iron results in strength considerably higher than of plain Fe combined with at least comparable ductility [1-6].

This positive effect of $\mathrm{P}$ is in part attributed to $\mathrm{P}$ being a ferrite stabilizing element. In $\alpha$-iron, the diffusional processes are much faster than in $\gamma$-iron which is the modification normally stable at sintering temperature [7], and sintering thus also proceeds at a much higher rate, 
similar to the effect of Mo addition [8]. Furthermore, $\mathrm{P}$ forms a transient liquid phase with $\mathrm{Fe}$ due to the low temperature of the Fe-P eutectic of only about $1050^{\circ} \mathrm{C}$ [9], at least at higher heating rates [10], which also accelerates sintering. In industrial practice, addition of $P$ as an activator to PM steels is popular because it enables sintering in standard mesh belt furnaces, at temperatures of about $1120 \mathrm{oC}$, while obtaining properties that in the case of P-free steels, would require temperatures exceeding $1200^{\circ} \mathrm{C}$ and thus walking beam furnaces.

However, there have been also numerous reports about embrittlement phenomena in P containing sintered steels. These effects are attributed e.g. to the transient liquid phase which leaves oxide traces at the grain boundaries [11] or to impurities contained by the ferrophosphorus used [12]. Small amounts of carbon reportedly are beneficial towards the mechanical behaviour $[\overline{13}, 14]$.

Among alloyed steels, the classical Ni-Cu-Mo types, which are also available as diffusion bonded grades, have been and still are successfully sintered with addition of phosphorus. Recently, however, $\mathrm{Ni}$ and $\mathrm{Cu}$ as alloy metals have become increasingly problematic, in part due to the high cost and volatile price of these alloy elements [15], in part due to health problems linked to $\mathrm{Ni}$ and the recycling difficulties with $\mathrm{Cu}$ that tends to be enriched in steel. Therefore, PM steels alloyed exclusively with VI group elements $(\mathrm{Cr}$, Mo, W) have become more and more popular. The first of these elements to find large scale industrial application was Mo, which gives attractive mechanical and heat treatment properties (e.g. [16-18]) while being uncritical with respect to the purity of the sintering atmosphere, due to the low thermodynamic stability of its oxides. Mo alloy steels can be produced from mixes, but for several compositions also prealloyed Fe-Mo powder grades are available. For these steels, the sintering behaviour and the properties in the presence of $\mathrm{P}$ are of considerable interest, in particular since embrittlement effects have been reported with Mo as with $\mathrm{Cr}[19,20]$. Within this work, steels alloyed with different amounts of Mo and $\mathrm{P}$, respectively, have been studied with regard to microstructure, mechanical properties and fracture behaviour.

\section{Experimental technique}

The specimens were prepared both through the mixing and the prealloying route, respectively, with regard to Mo addition. The manufacturing route followed the procedure described e.g. in [21]: Starting powders were iron powder grade ASC 100.29, prealloyed Fe-Mo powder Astaloy Mo (Fe-1.5\%Mo), both from Höganäs $\mathrm{AB}$, and natural graphite Kropfmühl UF4 (purified grade, ash content $<1 \%$ ). Mo was added as fine elemental powder $<32 \mu \mathrm{m}$ (Plansee SE), and Fe3P was chosen as P source (supplied by MIBA Sinter Austria $\mathrm{GmbH}$ ). $0.5 \%$ HWC was used as pressing lubricant. Mixtures of the desired compositions were prepared in a tumbling mixer, dry mixing being done for $1 \mathrm{hr}$. The mixes were then compacted at $700 \mathrm{MPa}$ to non-standard tensile test bars with die cavity cross section of 456 $\mathrm{mm}^{2}$ (see [17]) and sintered either in a pushtype furnace (Degussa "Baby") in flowing hydrogen - to avoid decarburization, getter boxes with $\mathrm{Al}_{2} \mathrm{O}_{3}-5 \% \mathrm{C}$ getter were used - or dewaxed in the pusher furnace at $600^{\circ} \mathrm{C}$ and then sintered in a chamber vacuum furnace under rotary pump vacuum (cold: approx. 10-2 mbar). In both furnaces, sintering was done isothermally at $1120^{\circ} \mathrm{C}$ and $1200^{\circ} \mathrm{C}$, respectively, for $1 \mathrm{hr}$ (pusher furnace) or $2 \mathrm{hrs}$ (vacuum furnace), the effective temperature being controlled pyrometrically, which implies that the real temperature may be slightly higher since the emissivity of the steel boats used is typically $<1$. The heating and cooling rates differed considerably, in the pusher furnace $+60 \ldots 80 \mathrm{~K} / \mathrm{min}$ (linearized) being typical while in vacuum $+10 \mathrm{~K} / \mathrm{min}$ was set, cooling however being considerably slower esp. in the low temperature range $<500^{\circ} \mathrm{C}$. 
The sintered samples were then tested following standard techniques, i.e. the green density was measured from the dimensions and the sintered density by water displacement after impregnation with a commercial waterstop spray. Furthermore, dimensional change during sintering (relative to the dimensions of the green compacts) and hardness HV30 were measured. Tensile tests were done on a universal testing machine Zwick 1474, and Charpy impact testing was performed on a Wolpert tester with $\mathrm{Wmax}=50 \mathrm{~J}$, at least 3 parallel specimens being tested each. For the impact tests it should be considered that the cross section of the bars tested here was markedly smaller than that of the ISO 5754 test specimens (about $6 \times 6 \mathrm{~mm}$ compared to $10 \times 10 \mathrm{~mm}$ for the standard bars), therefore the values should not be taken absolutely but just compared to one another. The fracture surfaces were studied by scanning electron microscopy.

For metallographic characterization, sections were prepared by cutting pieces from the heads of the sintered bars, resin mounting, grinding with $\mathrm{SiC}$ paper, diamond polishing with $15 / 7 / 3 \mu \mathrm{m}$ diamond paste and then finish polishing with fine Al2O3. Etching was done with Nital $\left(\mathrm{MeOH}-3 \% \mathrm{HNO}_{3}\right)$.

\section{Mechanical properties}

The properties obtained are listed in Tables 1-4; selected diagrams (Fig.1) show the relationships between properties and the P content (for the Mo-free steels see [21]). The scatter of the individual values was fairly low, in the range common for sintered steels, except for the explicitly brittle specimens for which wide scatter was encountered both in tensile and impact testing.

Tab.1. Properties of Fe-Mo-0.7C-P, compacted at $700 \mathrm{MPa}$, sintered 60 min at $1120^{\circ} \mathrm{C}$ in $\mathrm{H}_{2} /$ pusher furnace ( $\mathrm{C}$ content given as admixed graphite).

\begin{tabular}{|c|c|c|c|c|c|c|c|c|}
\hline & $\begin{array}{c}\text { P content } \\
\text { Mass } \%\end{array}$ & $\begin{array}{c}\text { G. Density } \\
\text { g.cm-3 }\end{array}$ & $\begin{array}{c}\text { S.Density } \\
\text { g.cm-3 }\end{array}$ & $\begin{array}{c}\text { Dim.Change } \\
\text { \%linear }\end{array}$ & $\begin{array}{c}\text { UTS } \\
\text { MPa }\end{array}$ & $\begin{array}{c}\text { A } \\
\%\end{array}$ & $\begin{array}{c}\text { IE } \\
\text { J.cm-2 } 2\end{array}$ & $\begin{array}{c}\text { HV } \\
\text { HV30 }\end{array}$ \\
\hline $0.5 \mathrm{Mo}$ & 0 & 7.20 & 7.28 & -0.10 & 441 & 3.6 & 13.5 & 140 \\
\hline & 0.15 & 7.19 & 7.18 & 0.12 & 513 & 3.76 & 16.3 & 165 \\
\hline & 0.3 & 7.18 & 7.10 & 0.32 & 592 & 3.82 & 16.8 & 176 \\
\hline & 0.45 & 7.17 & 7.08 & 0.67 & 619 & 2.08 & 12.0 & 190 \\
\hline & 0.6 & 7.14 & 7.07 & 0.55 & 656 & 1.18 & 8.2 & 218 \\
\hline $1.0 \mathrm{Mo}$ & 0 & 7.21 & 7.26 & 0.06 & 447 & 2.56 & 12.0 & 151 \\
\hline & 0.15 & 7.20 & 7.19 & 0.35 & 565 & 2.67 & 13.0 & 177 \\
\hline & 0.3 & 7.19 & 7.07 & 0.70 & 666 & 1.82 & 6.5 & 223 \\
\hline & 0.45 & 7.16 & 7.04 & 1.03 & 489 & 1.13 & 3.2 & 315 \\
\hline & 0.6 & 7.15 & 7.05 & 1.00 & 245 & 0.98 & 3.4 & 323 \\
\hline $1.5 \mathrm{Mo}$ & 0 & 7.22 & 7.25 & 0.14 & 486 & 2.36 & 12.0 & 160 \\
\hline & 0.15 & 7.21 & 7.17 & 0.39 & 516 & 1.92 & 12.1 & 184 \\
\hline & 0.3 & 7.18 & 7.05 & 0.89 & 562 & 1.37 & 5.9 & 242 \\
\hline & 0.45 & 7.16 & 6.99 & 1.37 & 205 & 0.78 & 2.0 & 315 \\
\hline & 0.6 & 7.15 & 7.01 & 1.21 & 199 & 0.64 & 1.9 & 366 \\
\hline AstMo & 0 & 7.18 & 7.31 & -0.07 & 589 & 2.88 & 11.1 & 206 \\
\hline & 0.15 & 7.17 & 7.21 & -0.03 & 633 & 2.14 & 10.3 & 210 \\
\hline & 0.3 & 7.15 & 7.15 & 0.02 & 684 & 1.43 & 6.0 & 278 \\
\hline & 0.45 & 7.14 & 7.09 & 0.13 & 433 & 0.96 & 2.1 & 385 \\
\hline & 0.6 & 7.13 & 7.10 & 0.09 & 216 & 0.91 & 1.2 & 454 \\
\hline
\end{tabular}


Tab.2. Properties of Fe-Mo-0.7C-P, compacted at $700 \mathrm{MPa}$, sintered $120 \mathrm{~min}$ at $1120^{\circ} \mathrm{C}$ in vacuum furnace ( $\mathrm{C}$ content given as admixed graphite).

\begin{tabular}{|c|c|c|c|c|c|c|c|c|}
\hline & P content & G. Density & S.Density & Dim.Change & UTS & A & IE & HV \\
\hline $0.5 \mathrm{Mo}$ & 0 & 7.20 & 7.26 & -0.18 & 427 & 6.3 & 20.7 & 114 \\
\hline & 0.15 & 7.19 & 7.18 & -0.07 & 482 & 4.9 & 18.9 & 140 \\
\hline & 0.3 & 7.18 & 7.11 & 0.12 & 548 & 4.8 & 17.7 & 150 \\
\hline & 0.45 & 7.17 & 7.09 & 0.34 & 572 & 4.6 & 15.3 & 171 \\
\hline & 0.6 & 7.14 & 7.07 & 0.70 & 570 & 3.2 & 11.0 & 177 \\
\hline $1.0 \mathrm{Mo}$ & 0 & 7.21 & 7.27 & -0.06 & 468 & 4.4 & 17.6 & 140 \\
\hline & 0.15 & 7.20 & 7.20 & -0.03 & 547 & 4.2 & 16.2 & 165 \\
\hline & 0.3 & 7.19 & 7.09 & 0.28 & 607 & 3.0 & 11.8 & 191 \\
\hline & 0.45 & 7.16 & 7.04 & 0.72 & 666 & 2.1 & 7.1 & 206 \\
\hline & 0.6 & 7.15 & 7.04 & 1.30 & 669 & 1.1 & 5.4 & 223 \\
\hline $1.5 \mathrm{Mo}$ & 0 & 7.22 & 7.30 & -0.03 & 506 & 3.0 & 14.3 & 160 \\
\hline & 0.15 & 7.21 & 7.21 & 0.02 & 606 & 2.8 & 13.1 & 184 \\
\hline & 0.3 & 7.18 & 7.08 & 0.32 & 700 & 2.3 & 11.1 & 206 \\
\hline & 0.45 & 7.16 & 7.00 & 1.15 & 670 & 1.1 & 7.5 & 242 \\
\hline & 0.6 & 7.15 & 7.01 & 1.86 & 478 & 1.0 & 4.8 & 263 \\
\hline AstMo & 0 & 7.18 & 7.31 & -0.25 & 622 & 3.8 & 15.4 & 184 \\
\hline & 0.15 & 7.17 & 7.23 & -0.21 & 732 & 3.4 & 12.5 & 198 \\
\hline & 0.3 & 7.15 & 7.31 & -0.14 & 876 & 3.0 & 11.8 & 227 \\
\hline & 0.45 & 7.14 & 7.13 & -0.02 & 745 & 1.0 & 8.3 & 242 \\
\hline & 0.6 & 7.13 & 7.13 & 0.02 & 263 & 1.0 & 5.0 & 275 \\
\hline
\end{tabular}

Tab.3. Properties of Fe-Mo-0.7C-P, compacted at $700 \mathrm{MPa}$, sintered $60 \mathrm{~min}$ at $1200^{\circ} \mathrm{C}$ in $\mathrm{H}_{2} /$ pusher furnace ( $\mathrm{C}$ content given as admixed graphite).

\begin{tabular}{|l|r|r|r|r|r|r|r|r|}
\hline & P content & G. Density & S.Density & Dim.Change & UTS & A & IE & HV \\
\hline $0.5 \mathrm{Mo}$ & 0 & 7,20 & 7,23 & $-0,07$ & 620 & 4,7 & 31,5 & 177 \\
\hline & 0,15 & 7,19 & 7,12 & 0,25 & 669 & 5,3 & 27,6 & 189 \\
\hline & 0,3 & 7,18 & 7,03 & 0,47 & 712 & 4,4 & 25,0 & 191 \\
\hline & 0,45 & 7,17 & 7,01 & 0,75 & 681 & 3,0 & 21,4 & 194 \\
\hline & 0,6 & 7,14 & 7,00 & 0,50 & 245 & 0,5 & 1,9 & 232 \\
\hline $1.0 \mathrm{Mo}$ & 0 & 7,21 & 7,18 & 0,14 & 660 & 3,9 & 20,0 & 191 \\
\hline & 0,15 & 7,20 & 7,08 & 0,47 & 739 & 5,1 & 25,2 & 211 \\
\hline & 0,3 & 7,19 & 6,94 & 1,05 & 652 & 1,8 & 5,5 & 285 \\
\hline & 0,45 & 7,16 & 6,94 & 1,19 & 268 & 0,9 & 1,1 & 301 \\
\hline & 0,6 & 7,15 & 7,02 & 1,09 & 265 & 0,8 & 1,7 & 331 \\
\hline $1.5 \mathrm{Mo}$ & 0 & 7,22 & 7,19 & 0,29 & 800 & 1,0 & 29,4 & 218 \\
\hline & 0,15 & 7,21 & 7,04 & 0,76 & 592 & 1,7 & 24,7 & 232 \\
\hline & 0,3 & 7,18 & 6,89 & 1,37 & 536 & 1,3 & 4,0 & 315 \\
\hline & 0,45 & 7,16 & 6,82 & 1,54 & 373 & 0,9 & 1,4 & 331 \\
\hline & 0,6 & 7,15 & 6,91 & 0,90 & 130 & 0,5 & 3,0 & 366 \\
\hline AstMo & 0 & 7,18 & 7,26 & $-0,18$ & 740 & 2,3 & 21,4 & 210 \\
\hline & 0,15 & 7,17 & 7,14 & 0,09 & 864 & 2,9 & 21,5 & 232 \\
\hline & 0,3 & 7,15 & 7,08 & 0,18 & 830 & 1,5 & 14,5 & 315 \\
\hline & 0,45 & 7,14 & 7,07 & 0,27 & 258 & 0,4 & 1,3 & 383 \\
\hline & 0,6 & 7,13 & 7,09 & 0,03 & 204 & 0,9 & 1,1 & 496 \\
\hline
\end{tabular}


Tab.4. Properties of Fe-Mo-0.7C-P, compacted at $700 \mathrm{MPa}$, sintered $120 \mathrm{~min}$ at $1120^{\circ} \mathrm{C}$ in vacuum furnace ( $\mathrm{C}$ content given as admixed graphite).

\begin{tabular}{|l|r|r|r|r|r|r|r|r|}
\hline & P content & G. Density & S.Density & Dim.Change & UTS & A & IE & HV \\
\hline 0.5 Mo & 0 & 7,20 & 7,27 & $-0,25$ & 517 & 7,1 & 27,2 & 136 \\
\hline & 0,15 & 7,19 & 7,17 & $-0,12$ & 574 & 5,3 & 26,1 & 157 \\
\hline & 0,3 & 7,18 & 7,10 & 0,04 & 605 & 4,7 & 20,9 & 171 \\
\hline & 0,45 & 7,17 & 7,04 & 0,27 & 635 & 4,6 & 18,5 & 184 \\
\hline & 0,6 & 7,14 & 6,99 & 0,20 & 441 & 0,8 & 1,8 & 223 \\
\hline 1.0 Mo & 0 & 7,21 & 7,30 & $-0,10$ & 591 & 5,4 & 23,8 & 163 \\
\hline & 0,15 & 7,20 & 7,20 & 0,07 & 677 & 4,7 & 24,7 & 181 \\
\hline & 0,3 & 7,19 & 7,07 & 0,63 & 728 & 1,6 & 8,9 & 237 \\
\hline & 0,45 & 7,16 & 6,99 & 0,67 & 720 & 1,5 & 8,1 & 242 \\
\hline & 0,6 & 7,15 & 7,02 & 0,87 & 626 & 1,1 & 4,4 & 252 \\
\hline 1.5 Mo & 0 & 7,22 & 7,31 & $-0,07$ & 639 & 4,2 & 22,9 & 184 \\
\hline & 0,15 & 7,21 & 7,19 & 0,36 & 710 & 4,0 & 20,4 & 194 \\
\hline & 0,3 & 7,18 & 7,06 & 0,72 & 806 & 2,3 & 11,7 & 242 \\
\hline & 0,45 & 7,16 & 6,88 & 1,26 & 798 & 1,3 & 6,6 & 252 \\
\hline & 0,6 & 7,15 & 6,90 & 1,23 & 552 & 0,8 & 3,0 & 294 \\
\hline AstMo & 0 & 7,18 & 7,32 & $-0,36$ & 637 & 4,4 & 23,5 & 187 \\
\hline & 0,15 & 7,17 & 7,26 & $-0,27$ & 704 & 3,6 & 18,4 & 210 \\
\hline & 0,3 & 7,15 & 7,20 & $-0,10$ & 712 & 1,6 & 12,2 & 252 \\
\hline & 0,45 & 7,14 & 7,16 & $-0,07$ & 853 & 1,0 & 8,8 & 287 \\
\hline & 0,6 & 7,13 & 7,17 & $-0,18$ & 250 & 0,6 & 4,0 & 315 \\
\hline
\end{tabular}

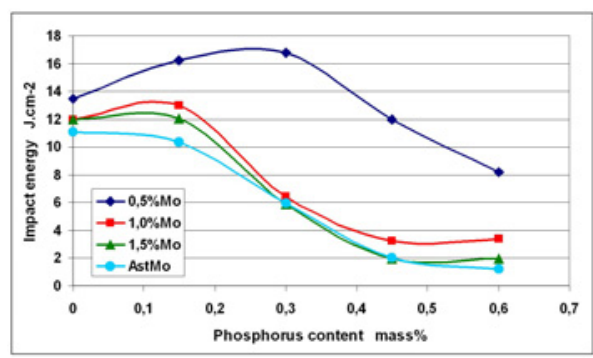

a) $1120^{\circ} \mathrm{C}$, pusher furnace / $\mathrm{H}_{2}$

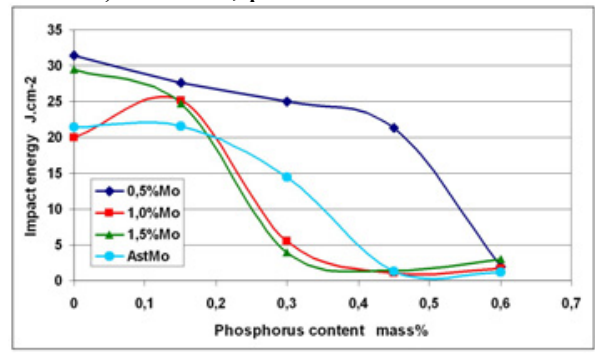

c) $1200^{\circ} \mathrm{C}$, pusher furnace $/ \mathrm{H}_{2}$

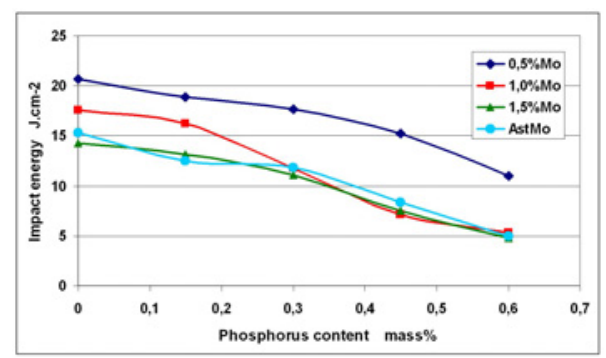

b) $1120^{\circ} \mathrm{C}$, vacuum furnace

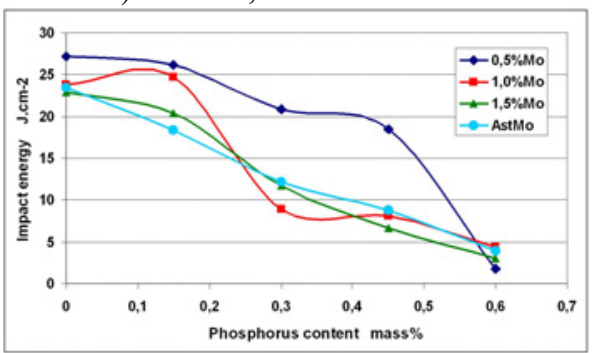

d) $1200^{\circ} \mathrm{C}$, vacuum furnace

Fig. 1. Impact energy of $\mathrm{Fe}-\mathrm{x} \% \mathrm{Mo}-0.7 \% \mathrm{C}-\mathrm{y} \% \mathrm{P}$ as a function of the $\mathrm{P}$ content. Compacted at $700 \mathrm{MPa}$; sintered $1 \mathrm{~h}$ in $\mathrm{H}_{2} / 2 \mathrm{~h}$ in vacuum. 
Generally it was found that the hardness and to some extent also the tensile strength of the materials increased with higher Mo and $\mathrm{P}$ content in part also due to sinter hardening, and the elongation and impact energy decreased. This can be regarded as a normal behaviour, not only for sintered but also for wrought steels. It was however noticed that for every material there is a given $\mathrm{P}$ concentration exceeding of which resulted in an out-of-proportion lowering of the Charpy impact energy, and this effect is not attributable to a corresponding increase of the hardness, i.e. the materials are actually embrittled.

This can be clearly seen from Fig. 2 which depicts the ratio Rm/HV (which with PM steels can be regarded e.g. as an indicator for proper sintering [22, 23], a sort of "quality factor"), as a function of the phosphorus content. As visible, there is a pronounced drop in the graph for almost all Mo contents, but the P content at which this drop starts depends on the Mo content and also on the alloying technique; as visible e.g. from Fig.2c, the graph for $1.5 \%$ Mo admixed shows a drop already for addition of $0.15 \% \mathrm{P}$ while the same material prepared from prealloyed steel powder tolerates this $\mathrm{P}$ content, only at $0.30 \% \mathrm{P}$ a drop of $\mathrm{Rm} / \mathrm{HV}$ being observed. This indicates that formation of transient liquid phase, as typical for Mo steels from mixed powders [16], increases the tendency to embrittlement if also $\mathrm{P}$ is present, probably by formation of a liquid rich in $\mathrm{P}$ and $\mathrm{C}$ but also in Mo, which enhances subsequent formation of brittle intergranular/interparticle phases. The adverse effect of $\mathrm{P}$ containing transient liquid phase has already been described by Lindskog et al. [11]; in the present case there is the additional effect of Mo which with $\mathrm{P}$ forms fairly stable compounds (Mo3P decomposes peritectically at $\mathrm{T}>1600^{\circ} \mathrm{C}$ [9]).

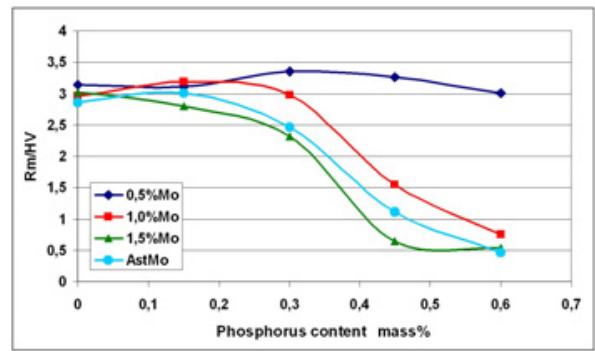

a) $1120^{\circ} \mathrm{C}$, pusher furnace $/ \mathrm{H}_{2}$

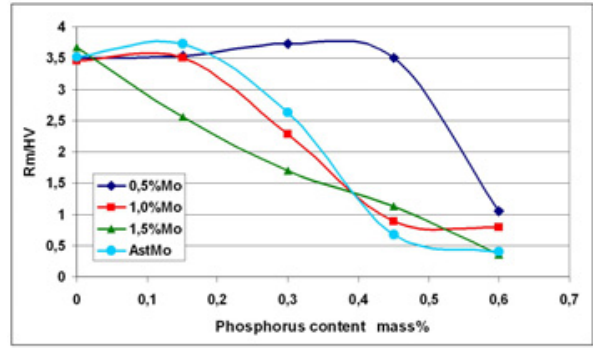

c) $1200^{\circ} \mathrm{C}$, pusher furnace $/ \mathrm{H}_{2}$

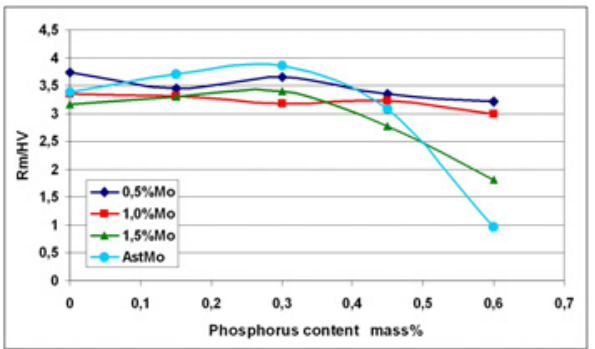

b) $1120^{\circ} \mathrm{C}$, vacuum

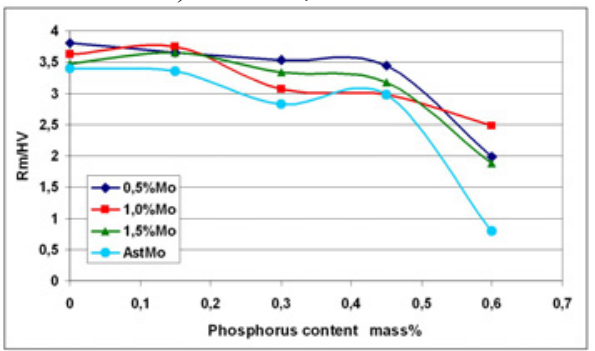

d) $1200^{\circ} \mathrm{C}$, vacuum

Fig.2. Ratio $\mathrm{Rm} / \mathrm{HV}$ as a function of the $\mathrm{P}$ content; different sintering temperatures and atmospheres/furnaces.

That formation of liquid phase is detrimental for the mechanical properties can also be derived from comparison of Fig.2c and d: for the materials sintered in vacuum, i.e. at significantly lower heating rates, a drop of the $\mathrm{Rm} / \mathrm{HV}$ ratio is observed only at $\mathrm{P}>$ $0.45 \%$ for all Mo levels and alloying techniques. 
The role of the liquid phase is also corroborated by the effect of the sintering temperature: when sintered at $1120^{\circ} \mathrm{C}$, the mixed Mo-P steels are markedly more tolerant to $\mathrm{P}$ than at $1200^{\circ} \mathrm{C}$. At $0.5 \% \mathrm{Mo}$, even $0.6 \% \mathrm{P}$ do not yet cause embrittlement when sintered at $1120^{\circ} \mathrm{C}$, and at $1.0 \%$ Mo the threshold for embrittlement is above $0.3 \% \mathrm{P}$ as compared to $0.15 \%$ for $1200^{\circ} \mathrm{C}$.

For sintering in vacuum, in contrast, there is hardly any effect of the sintering temperature (except at the highest $\mathrm{P}$ content of $0.6 \%$ ). This indicates that due to the much slower heating, phosphorus is distributed within the steel matrix already during the heating process, through solid state diffusion, and is no more available to form transient liquid phase with Mo.

Sinter hardening, which takes place at higher Mo and $\mathrm{P}$ contents, seems to aggravate the embrittlement but not to cause it since the latter effect itself is clearly noticeable also after vacuum sintering in which case the cooling rate is slow and the hardness is accordingly lower than after sintering in the pusher furnace. On the other hand, precipitation of Mo phosphides during cooling is also improbable since in this case lower cooling rates should result in more severe embrittlement, as known e.g. from heavy alloys [24]. Only in the case the precipitation takes place at fairly low temperatures the difference of the cooling rates in both furnaces is smaller, and similar results may be obtained, but at low temperatures diffusion of Mo (and, less pronounced, also of $\mathrm{P}$ can be expected to be fairly slow.

There is of course the question how significant the ratio $\mathrm{Rm} / \mathrm{HV}$ is for the mechanical behaviour in the present case. Therefore, this ratio was plotted against the Charpy impact energy for all materials investigated. The result is shown in Fig.3: As evident, there is a fairly clear relationship between the two parameters, but 2 sections of the graph can be observed: for $\mathrm{Rm} / \mathrm{HV}<3$, the impact energy values are generally low, and the slope of the linear graph by which the correlation can be approximated is also low. This range can be identified as that of brittle materials. At $\mathrm{Rm} / \mathrm{HV}>3$, the slope of the approximation here is much steeper, i.e. in an $\mathrm{Rm} / \mathrm{HV}$ ratio range of 3-4, the impact energy may vary between 5 and $30 \mathrm{~J} . \mathrm{cm}-2$. However, also here a positive correlation can be found, i.e. higher $\mathrm{Rm} / \mathrm{HV}$ tends to indicate also higher impact energy, which can be attributed to better interparticle bonding in reasonably ductile materials.

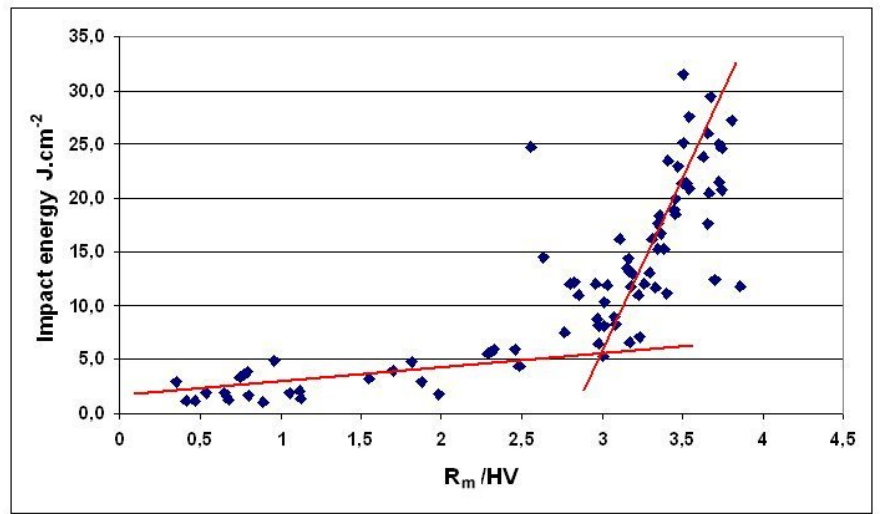

Fig.3. Impact energy of $\mathrm{Fe}-\mathrm{x} \% \mathrm{Mo}-0.7 \% \mathrm{C}-\mathrm{y} \% \mathrm{P}$ as a function of the ratio $\mathrm{Rm} / \mathrm{HV}$. Data from Tables 1-4. 


\section{Metallography and fractography}

Metallographic investigation of the materials confirmed the progressive pore rounding and pore coarsening caused by phosphorus, as a result of the lowering of the solidus temperature by $\mathrm{P}$ addition (Fig.4). Increasing the phosphorus content thus is comparable to increasing the sintering temperature. In particular for the steels prepared from mixed powders, also the formation of transient liquid phase with resulting formation of secondary pores should be considered. At $0.7 \% \mathrm{C}$, the formation of transient liquid phase in Fe-Mo-C starts at about $1240^{\circ} \mathrm{C}$, but with increasing $\mathrm{P}$ content this temperature threshold is lowered, similar to the effect of increasing the $\mathrm{C}$ content. This further enhances pore coarsening [25].

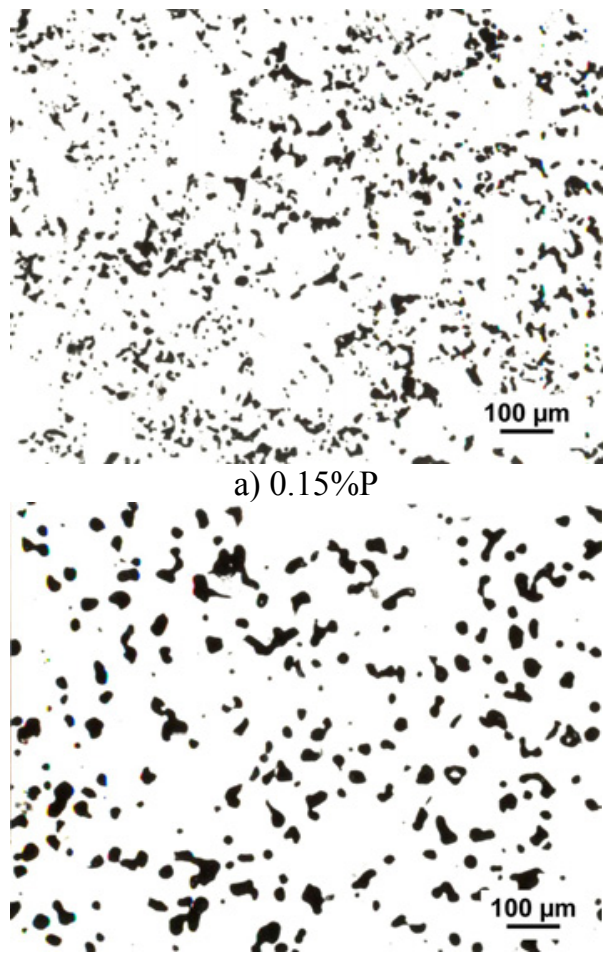

c) $0.45 \% \mathrm{P}$

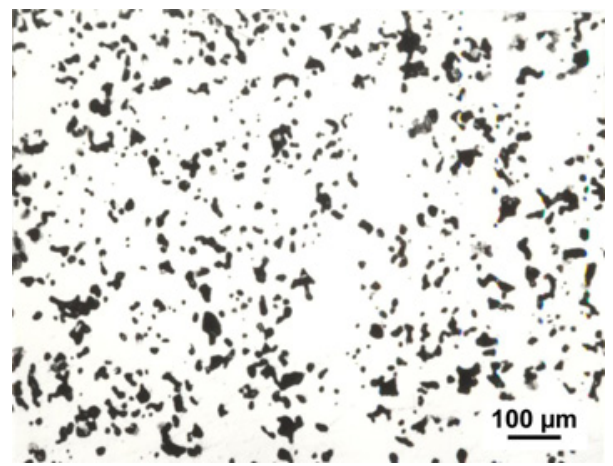

b) $0.30 \% \mathrm{P}$

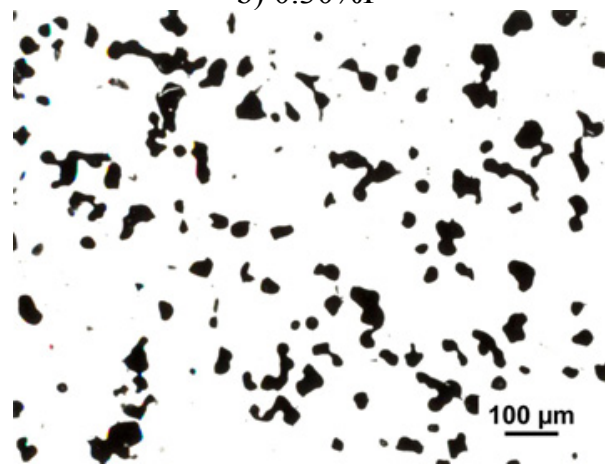

d) $0.60 \% \mathrm{P}$

Fig.4. Metallographic sections of Fe- $1.5 \% \mathrm{Mo}-0.7 \% \mathrm{C}-\mathrm{x} \% \mathrm{P}$, sintered at $1200^{\circ} \mathrm{C}$ in the pusher furnace $/ \mathrm{H}_{2}$.

It was also clearly visible that the addition of phosphorus to Mo alloyed steel, at least at the carbon level given here, results in pronounced sinter hardening behaviour at least if the cooling rate is not too low. The martensitic structures obtained after sintering in the pusher furnace, with its fairly fast cooling further enhanced by the $\mathrm{H}_{2}$ atmosphere, are clearly visible (Fig.5b) compared to the very fine bainite in the P-free steel (Fig.5a). The high hardness of the Mo and P containing steels is thus easily explained. Slower cooling, as in the case of vacuum sintering, results is the relatively coarse upper bainite typical for assintered Mo steels. Esp. in the case of Mo prealloying it is evident that there is hardly any effect of the P content on the microstructure (Fig.5c, d). 


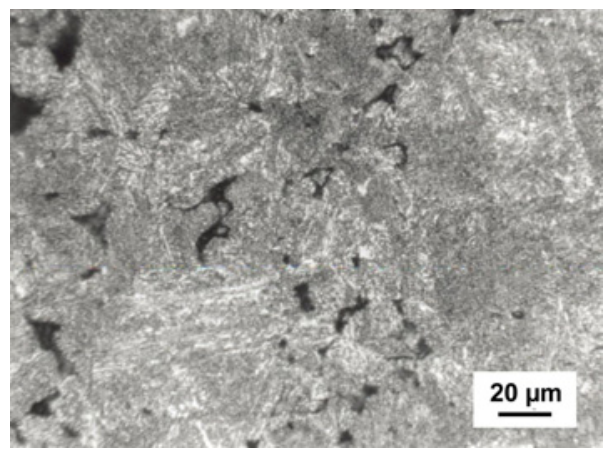

a) $0.0 \% \mathrm{P}, \mathrm{H}_{2}$

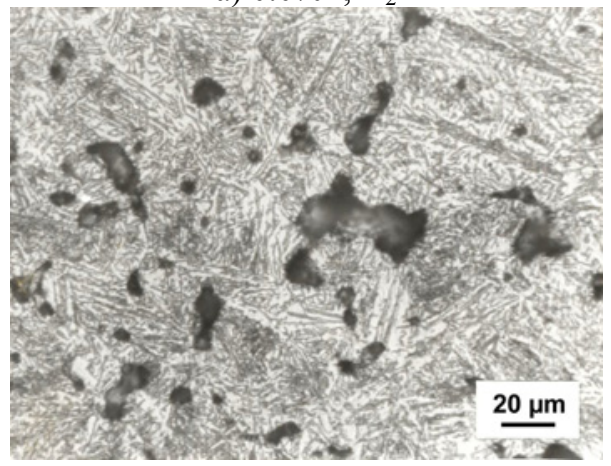

c) $0.15 \% \mathrm{P}$, vacuum

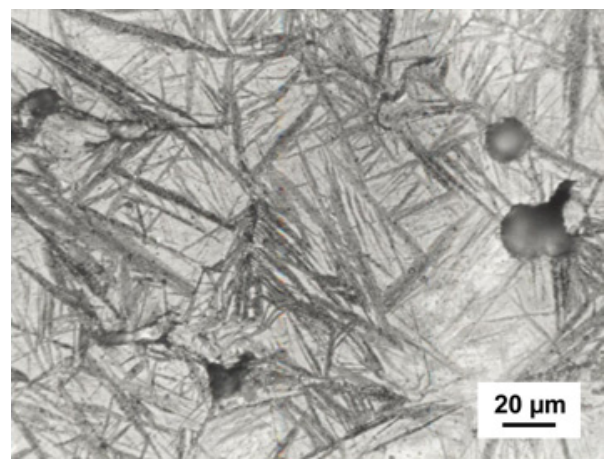

b) $0.60 \% \mathrm{P}, \mathrm{H}_{2}$

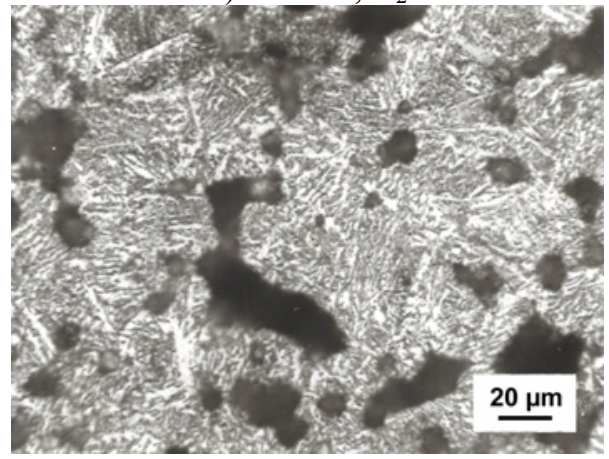

d) $0.60 \% \mathrm{P}$, vacuum

Fig.5. Fe-1.5\%Mo-0.7\%C-P (AstaloyMo), sintered at $1120^{\circ} \mathrm{C}$ in different atmospheres.

The sections also revealed the favourable effect of $\mathrm{P}$ on the homogenization of Mo during sintering. If Mo is added as elemental powder, sintering at low temperatures (below $1240^{\circ} \mathrm{C}$ for $0.7 \% \mathrm{C}$ ) results in only insignificant homogenization, the Mo particles being transformed into $\eta$ carbides but remaining largely undissolved. If phosphorus is added, the solidus temperature is lowered and transient liquid phase is formed already at lower temperature, with beneficial effects on the distribution of Mo within the matrix (e.g. Fig.5b, 6a) but adverse ones on the mechanical properties, as shown above. If temperature and/or $\mathrm{P}$ content are still higher, persistent liquid phase is formed that leaves brittle eutectic at the grain boundaries (Fig.6b). This agrees with thermodynamic calculations using ThermoCalc $\AA$ software which showed that the solidus temperature pronouncedly decreases with higher $\mathrm{P}$ content while the effect of Mo is much less pronounced and virtually independent of the P content (Fig.7a). There is some discrepancy between simulation and experiment insofar as persistent liquid phase was clearly observed after sintering at $1200^{\circ} \mathrm{C}$ while according to the calculations this temperature should just be the threshold for melt formation. This can be explained by the difficulty to precisely predict exact temperatures through simulation (to some extent also to measure effective temperatures in a high temperature furnace, as stated above). 


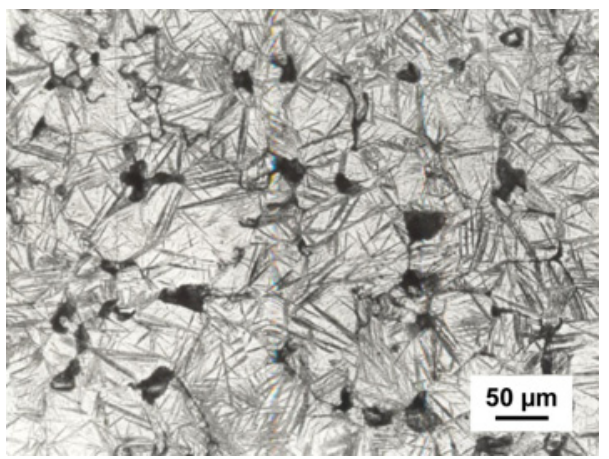

a) $1120 \mathrm{oC}$

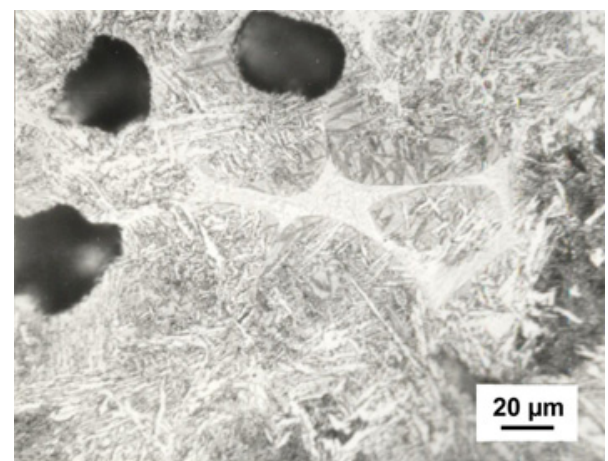

b) $1200 \mathrm{oC}$

Fig.6. Fe-1.5\%Mo-0.7\%C-0.6\%P, sintered in the pusher furnace $/ \mathrm{H}_{2}$ at different temperatures.

The simulation also showed that the temperature "window" between solidus and liquidus is markedly widened by $\mathrm{P}$ addition (Fig.7b), once more corroborating the experimental observation that $\mathrm{P}$ addition renders a ferrous system more tolerant to variations of the sintering temperature.

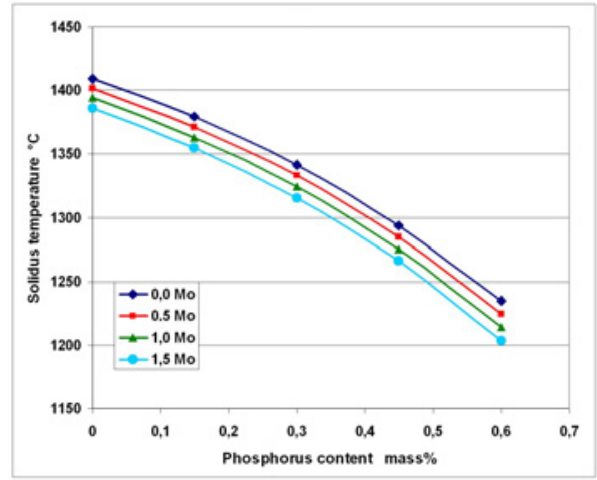

Fig.7a. Calculated solidus temperatures for $\mathrm{Fe}-\mathrm{x} \% \mathrm{Mo}-0.65 \% \mathrm{C}-\mathrm{y} \% \mathrm{P}$ as a function of the $\mathrm{P}$ content.

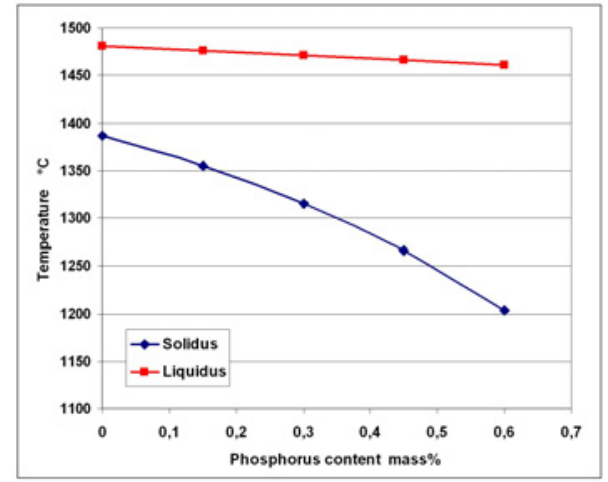

Fig.7b. Calculated solidus and liquidus temperatures of $\mathrm{Fe}-1.5 \% \mathrm{Mo}-0.65 \% \mathrm{C}-\mathrm{P}$ as a function of the $\mathrm{P}$ content.

The formation of the brittle eutectic phase of course can explain only for the brittleness of the high temperature sintered, high $\mathrm{P}$ materials but not for embrittlement of those within which no persistent liquid phase has been formed. These materials, e.g. steels sintered at $1120 \mathrm{oC}$, should rather exhibit better properties than similar steels without $\mathrm{P}$, since Mo homogenization results in significant improvement especially of the impact energy [17].

Fractographic investigations revealed that the embrittlement observed is mostly due to a different fracture mechanism. While as-sintered Mo steels - Fe-Mo-C without or with only low amounts of phosphorus - exhibit in part ductile rupture, in part transgranular cleavage fracture (see e.g. Fig.8a,c), the strongly embrittled materials containing both Mo and $\mathrm{P}$ at higher concentrations show pronounced intergranular failure both in the cases of static tensile and of impact loading (Fig.8b, d). This indicates that there is actually interfacial embrittlement, apparently caused by weakening of the grain boundaries (i.e. more or less the 
sintering contacts), which is a phenomenon well known from $\mathrm{P}$ containing ferrous sintered materials especially at higher P levels; AES studies have confirmed P segregation there [26].

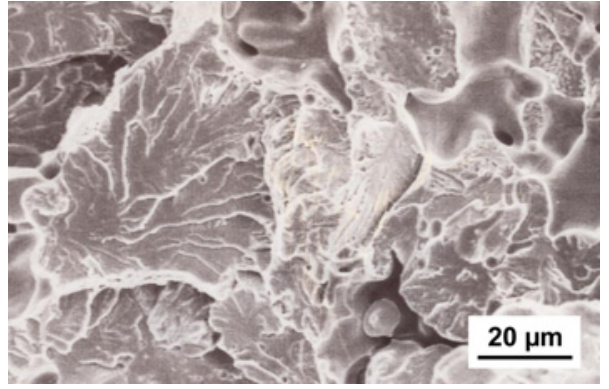

a) $0.30 \% \mathrm{P}$, tensile loading

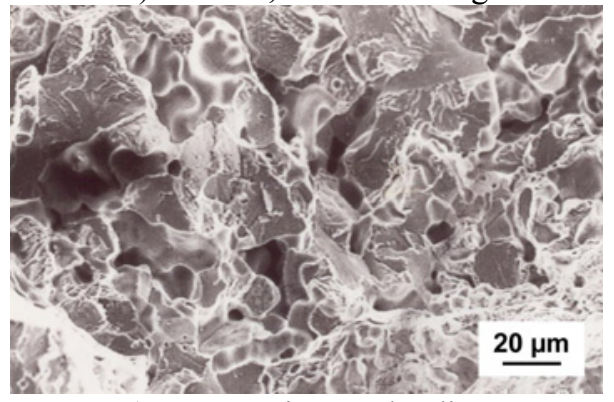

c) $0.30 \% \mathrm{P}$, impact loading

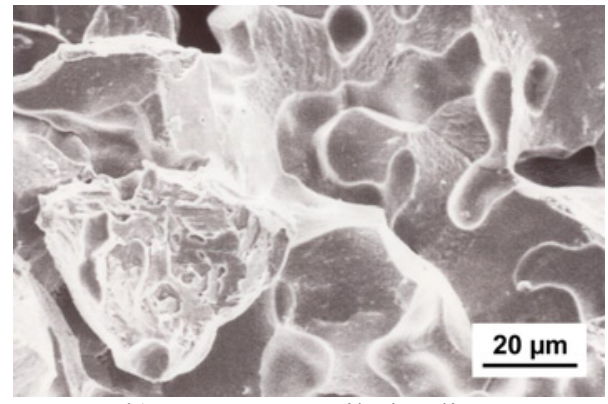

b) $0.45 \% \mathrm{P}$, tensile loading

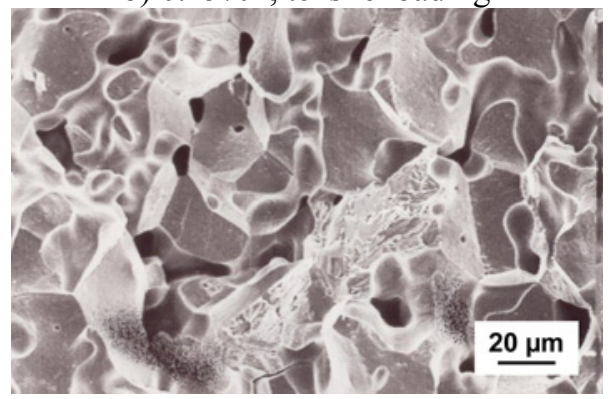

d) $0.45 \% \mathrm{P}$, impact loading

Fig.8. Fracture surfaces of Fe- $1.5 \% \mathrm{Mo}-0.7 \% \mathrm{C}-\mathrm{P}$, sintered in the pusher furnace $/ \mathrm{H}_{2}$ at $1120^{\circ} \mathrm{C}$

Also in the fracture surfaces the effect of heating rate - and therefore of formation of transient liquid phase - is evident: while in the case of rapidly heated specimens with higher $\mathrm{P}$ content intergranular fracture dominates, as visible from Figs.8b, d, after sintering in vacuum even at very high $P$ levels transgranular cleavage dominates (Fig.9), and there are hardly any intergranular facets visible. This agrees with the mechanical properties which had shown markedly less tendency to embrittlement in case of vacuum sintering, with lower heating rate, compared to sintering in the pusher furnace.

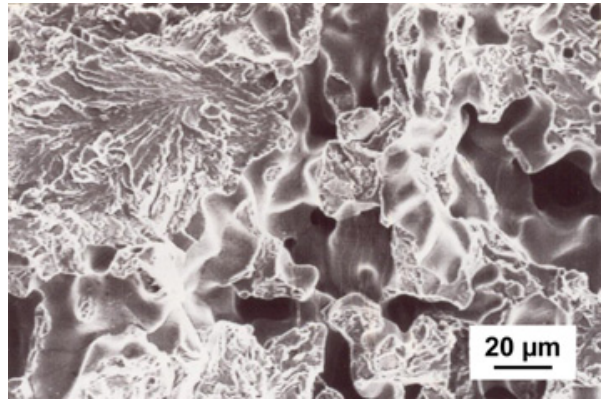

a) $0.3 \% \mathrm{P}$

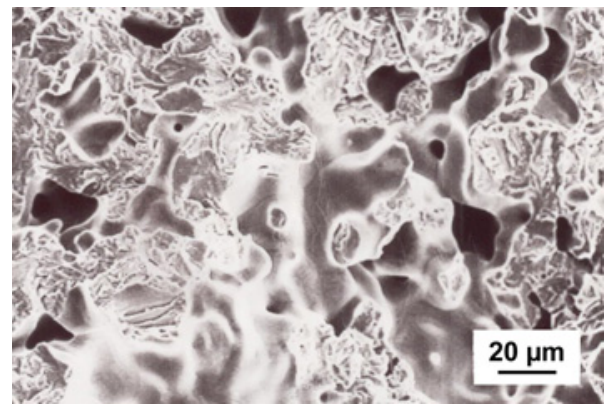

b) $0.6 \% \mathrm{P}$

Fig.9. Fracture surfaces of Fe- $1.5 \% \mathrm{Mo}-0.7 \% \mathrm{C}-\mathrm{P}$, sintered in the vacuum furnace at $1120^{\circ} \mathrm{C}$. 
In principle, the embrittlement caused by $\mathrm{P}$ reminds of the well known temper embrittlement encountered with wrought steels, in particular $\mathrm{Cr}$ and $\mathrm{Mn}$ alloyed ones (e.g. [27], which type of embrittlement is also attributed to phosphorus traces, although in wrought steels it is rather prevented by Mo addition, which element is present here in considerable amounts. However, it must be remembered that also the $\mathrm{P}$ content is much higher here than in the case of the embrittled wrought steels. It seems therefore that the embrittlement found here might be at least in part some sort of "temper" embrittlement occurring during the later stages of cooling. However, as stated above there seems to be also a contribution of the transient liquid phase generated by $\mathrm{P}$ since rapid heating - as done in the pusher furnace - results in markedly more pronounced embrittlement and also in more intergranular failure than slow heating as done in the vacuum furnace. Of course also the sinter hardening effect observed after sintering in the pusher furnace lowers the ductility, but it cannot be held responsible for the intergranular failure observed.

\section{Conclusions}

Molybdenum alloyed steels containing phosphorus exhibit embrittlement if the phosphorus content exceeds a certain limit. This limit is indicated by a drop of the impact energy and also of the ratio tensile strength/hardness. It is a function of the Mo content, at lower Mo concentrations more $\mathrm{P}$ being tolerable. The embrittlement effect is noticeable after sintering at $1120^{\circ} \mathrm{C}$ and more so at $1200 \mathrm{oC}$ and after sintering in a push type furnace (with fairly fast cooling) in $\mathrm{H}_{2}$ as well as after vacuum sintering, although it is most pronounced after sintering at $1200 \mathrm{oC}$ in $\mathrm{H}_{2}$. The effect of temperature is markedly more pronounced when sintering in the pushtype furnace, with high heating and cooling rates, than in the vacuum furnace, which indicates that formation of transient liquid phase is crucial for the embrittlement. After both tensile and impact testing, the embrittled materials show significant amounts of intergranular fracture, while standard as-sintered Mo alloy steels exhibit mixed ductile and cleavage fracture. This embrittlement seems to be due to grain boundary precipitation which might occur in the later stage of cooling, as known from temper embrittlement. However, as stated above transient - and at very high P levels also persistent - liquid phase and sinter hardening caused by $\mathrm{P}$ contribute to the brittleness of the Mo-P alloyed steels. It must therefore be concluded that using $\mathrm{P}$ as a sintering activator for Mo alloyed steels has do be done carefully to avoid unwelcome embrittlement, in particular high heating rates are to be avoided, which however are not typical for industrial practice anyhow.

\section{Acknowledgement}

The authors wish to thank Fa. MIBA Sinter Austria GmbH, Vorchdorf, for supplying the starting powders used, and Raquel de Oro Calderon, Vienna, for the thermodynamic calculations.

\section{References}

[1] Lenel FV: U.S.Pat. 2.226,520 (1940)

[2] Kieffer R, Hotop W: Sintereisen und Sinterstahl. Springer, Vienna (1948)

[3] Eisenkolb F: Arch. Eisenhüttenwesen 24 (1953) 257

[4] Jones WD: Fundamental Principles of Powder Metallurgy. Edward Arnold, London (1960)

[5] Lenel FV: Powder Metallurgy - Principles and Applications. MPIF, Princeton (1980)

[6] Šalak A: Ferrous Powder Metallurgy. Cambridge Int. Sci. Publ., Cambridge (1995)

[7] Höganäs Handbook for Sintered Components Vol.1 „Material and Powder Properties“, 
Höganäs AB, Höganäs (2004)

[8] Lindner KH, in: Pulvermetallurgie in Wissenschaft und Praxis Vol.11, H.Kolaska ed., DGM, Oberursel (1995) 159

[9] ASM Handbook Vol.3 „Alloy Phase Diagrams“, ASM, Materials Park OH (1992)

[10] Miura H, Tokunaga Y: Int. J. Powder Metall. \& Powder Technol. 21 (4)(1985) 269

[11] Lindskog P, Tengzelius J, Kvist SA: Modern Dev. in Powder Metall. 10 (1977) 97

[12] Tengzelius J: Metal Powder Rep. 48 (1)(1993) 36

[13] Molinari A, Fontanari V, Straffelini G, Canteri R: Powder Metall. 35 No.4 (1992) 285

[14] Lund J: Modern Dev. in Powder Metall. 16 (1985) 3

[15] Donaldson I, Marucci M, Lindsley B: Adv. Powder Metall. \& Partic. Mater. - 2011, compiled by Anderson IE, Pelletiers TW, MPIF, Princeton NJ Part 7, 54-63 (2011)

[16] Danninger H: Powder Metall. Int. 20 (4)(1988) 7

[17] Danninger H: Powder Metall. Int. 24 (2)(1992) 73

[18] Danninger H, Weiss B: Powder Metall. Progress 1 No.1 (2001), 19

[19] Danninger H, Üregen B, in: Adv. Structural Parts Prod., (Proc. EuroPM'97 Munich), EPMA, Shrewsbury UK (1997) 319

[20] Gierl-Mayer C, Jaliliziyaeian M, Danninger H, Dudrova E: Powder Metall. Progress 14 No.2 (2014) 73

[21] Üregen B, Gierl-Mayer C, Danninger H: Powder Metall. Progress 16 (2016), in press

[22] Momeni M, Gierl C, Danninger H: Powder Metall. Progress 8 No.3 (2008) 183

[23] Danninger H, Gierl C, Šalak A: Powder Metall. Progress 9 No.1 (2009) 1

[24] Muddle BC, Edmonds DV: Metal Sci. 17 (1983) 209

[25] Danninger H, Wolfsgruber G, Dalal K: Proc. PM'94 Powder Metall. World Congress 1994 Paris, SF2M, EPMA eds., Paris (1994) Vol.II, 875

[26] Vassileva V, Krecar D, Tomastik C, Gierl-Mayer C, Hutter H, Danninger H: Powder Metall. Progress 15 No.1 (2015) 36

[27] Ed.Houdremont: Handbuch der Sonderstahlkunde, Springer-Verlag Berlin-GöttigenHeidelberg (1956) 